\title{
Optimal Electricity Transmission Pricing in a Restructured Electricity Market
}

\author{
S. B. Warkad, Member, IACSIT, Dr. M. K. Khedkar, Dr. G. M. Dhole
}

\begin{abstract}
In last two decades, electricity markets have significantly restructured in both developed and developing countries. This restructuring introduced competition both wholesale and, in some cases, in the retail segments of the electric power industry. A common element of electricity restructuring is the unbundling of generation and transmission, with the latter being opened for use by all eligible market participants under the open access regime. Transmission pricing in open access regime is one of the active area of research. In developing countries, transmission pricing is mainly addressing the issue of recovering embedded cost or past investment and optimal allocation of variable cost at different nodes over the grid. Pricing methods should capable to translate transmission cost into tariffs to enable competition, lead to economic efficiency, enable the grid owner to recover his cost and more transparent to market participants while maintaining supply security and reliability of the system.

This study aims at (1) motivations for electricity transmission pricing, (2) formulating AC-DC OPF based embedded and nodal pricing (3) computing prices for IEEE 30-Bus system and real transmission network of India. Study finally concluded that proposed methodology are more suitable for developing countries to fulfill their objectives of developing wholesale electricity market.
\end{abstract}

Index Terms - AC-DC OPF, Embedded cost, Nodal pricing, Transmission pricing

\section{INTRODUCTION}

In last two decades, electricity markets have significantly restructured in both developed and developing countries. This restructuring introduced competition in both wholesale and, in some cases, in the retail segments of the electric power industry. The primary reason for introducing competition in the developed countries (e.g. North America and Western Europe) is to improve techno-economic efficiency. For fast developing countries (e.g. China and India), is to introduce competition and to attract private investment, thereby relieving the government in funding the electric sector's growth that is crucial to economic development [1].

A common element of electricity restructuring is the unbundling of generation and transmission, with the latter being opened for use by all eligible market participants under the so-called open access regime. This has greatly

S. B. Warkad is with the Department of Electrical Engineering, Visvesvaraya National Institute of Technology, Nagpur, Pin-440010, India. (Corresponding author to provide phone: +919923206720; fax: +91 07104-237681)

Dr. M. K. Khedkar is with the Department of Electrical Engineering, Visvesvaraya National Institute of Technology, Nagpur, Pin-440010.

Dr. G. M. Dhole Department of Electrical Engineering, Shri Sant Gajanan Maharaj College of Engineering, Shegaon, Pin-444203, India. transformed the traditional power industry and introduced many new challenges in all aspects of generation, transmission and system operation. In recent years, the electric power industry has entered in an increasingly competitive environment under which it becomes more realistic to improve economics and reliability of power systems by enlisting market forces. In developing countries, the trend of electricity market is heading towards Transmission Open Access (TOA) whereby transmission providers will be required to offer the basic transmission service (operational and/or ancillary services) and pricing.

In coming years, power consumption in developing countries have expected to more than double compared to 35 to 40 percent increase in developed countries. Besides, many developing countries are facing the problems of transmission congestions, infrastructure investment especially in transmission and distribution segment due to inadequate investments incurred in the past. To reduce the gap between transmission capacity and power demand, trend is now to adopt HVDC transmission system in the existing AC networks to gain advantages of the investment. This trend has therefore needed to address in formulating transmission pricing scheme.

In developing country like in India, the Electricity Act (EA) 2003 has implemented to undertake comprehensive market reforms in the electricity sector. TOA and National Tariff Policy by Ministry of Power, Government of India (GoI) seeks to achieve the objectives to develop efficient wholesale electricity markets. The proposed pricing scheme can be more suitable for similar developing countries.

After this introduction, section 2 provides rationale of the present work of electricity transmission pricing. Section 3 explains the objectives and need of modeling transmission pricing. Section 4 formulates AC-DC OPF based transmission fixed embedded cost methods and variable pricing in terms of optimal nodal pricing methodology. In section 5, transmission pricing methods have simulated and numerical results are presented for modified IEEE-30 Bus system and for real transmission network of India. Finally, the conclusion is presented in section 6 .

\section{RATIONALE FOR ELECTRICITY TRANSMISSION PRICING}

The electricity transmission pricing literature studies have reviewed as a background of the present work but with no intention to cover all the published work. [2] introduced the concept of embedded capital costs of marginal cost principle. [3] worked out wheeling rates. The sensitivities to losses, constraints, load levels, amount of power wheeled and 
revenue reconciliation etc., were examined on power system. [4] presented cost of transmission transaction by evaluating components like operating cost, opportunity cost, reinforcement cost, existing system cost, embedded cost, incremental cost and marginal cost to make correct economic decisions. [5] introduced load flow method for allocating the cost of transmission capacity. Embedded, incremental and marginal cost of transmission capacity are also defined and compared. [6] computed cost of wheeling methodologies and suggested the computational procedures and for Postage Stamp, Contract path, Boundary flow and MW-Mile methods of embedded cost. [7] derived a new method from the MW-Mile rule has been used to allocate transmission capital cost. The embedded cost methods were compared and the economic issue and the impact on the system expansion planning of such allocation were discussed. [8] introduced a novel analytical approach to allocate transaction costs. It employed a sensitivity index and line utilization factors to determine the incremental power flow on a line with respect to the power generation at all buses. Method is applicable to the multiple wheeling participants. [9] allocated the embedded cost of simultaneous bilateral transactions under deregulated environment of power system. The methods like Postage Stamp, Contact path, Boundary Flow, MW-Mile, MVA-Mile were numerically tested over South African power system. [10] presented a transmission pricing based on voltage angle allocation. It used a DC power flow to compute voltage angle decomposition and the primary solution is corrected in different iterations of decoupled Newton-Raphson power flow. The contribution of each contract on power flow of each transmission line is computed by voltage angle decomposition. [11] developed nodal price model by describing the meaning and numerical properties of the generation and transmission components based on "slack bus" and "system lambda". [12] an OPF have used for the decomposition of nodal prices to perform the operation of the Poolco model. Results have derived using the decomposition of the Lagrangian multipliers corresponding to power balance equations into components of generation, losses and system congestion. It also demonstrated the sensitivity of the congestion constraints due to generation and losses. [13] introduced the concept of nodal price into power systems and provided the foundation and starting point for most successive research. [15] presented an integrated nodal pricing model by modifying existing Newton OPF by Interior Point algorithms. It included derivation of optimal nodal specific real-time prices and the method to decompose it into generation, loss, and ancillary services such as spinning reserve, voltage control and security control. [16] presented a detailed description and components of nodal prices i.e. generation, transmission congestion, voltage limitations and other constraints. [17] discussed the pricing of marginal transmission network losses in the Locational Marginal Pricing (LMP) deployed in the ISO New England standard market design. Study achieved market-clearing results by introducing loss distribution factors to balance explicitly the consumed losses in the lossless DC power system. The distributed market slack references have also discussed. [18] provided explicit formulas to calculate components of LMPs i.e. reference price, congestion price, and loss price based on the single-slack power-flow formulation. [19] presented an approach for the allocation of transmission network costs by controlling the electricity nodal prices. It introduced generation and nodal injection penalties into the economic dispatch to create nodal price differences that recover the required transmission revenue from the resulting congestion rent. [20] presented electricity price forecasting techniques, can be useful at different time horizons for electricity price forecasting in LMP nodal markets. Fuzzy inference system, least-squares estimation, and the combination of both have proposed to improve the short-term forecasting performance. [21] provided an iterative DCOPF-based algorithm to calculate LMPs and to analyze the sensitivity of LMP with respect to the system load.

\section{TRANSMISSION PRICING OBJECTIVES AND NEED OF MODELLING NODAL PRICES}

\section{A. Pricing Objectives}

- Economic efficiency - A good transmission pricing system has to give correct incentives and improve economic efficiency of to the market participants. It should encourage an efficient use of the existing network, encourage investments in network expansion, encourage an efficient location of new generation units etc.

- Price Transparency and Non-discrimination- The transparency of pricing is a key in a restructured electricity markets. The prices should be non-discriminating to identical clients buying electricity at the same location on a grid and at the same time should also pay the same price.

- Cost coverage- transmission pricing should design to fully recover the transmission owner's costs (including a profit), efficient allocation of scarce (congested) transmission capacity, efficient allocation of the costs of transmission losses etc., and it should be based on marginal cost principle.

\section{B. Need of Modeling Prices}

In the restructured electricity markets, due to competition between the power generating companies and also the reductions in regulation and government price setting have led to wholesale electricity nodal prices becoming much more volatile. This further resulted electricity market participants facing increased risk, both in terms of volumes of electricity they can produce and sell, and the prices they will receive for their outputs. To facilitate market participants with respect to operations, risk management, and investment, need is to accurately model nodal price behaviour. Aside from generators, investors and consumers, regulatory bodies, also require models of nodal prices in order to study market behaviour. Also often forecast and models of nodal prices are required for many different applications in the operation of electricity markets. For example, in short-run, generating companies have to make decisions regarding unit commitment for efficient and profitable dispatched of their generators. These decisions are often required hours or days in advance, they require forecast of future nodal prices in order to determine profitability. In the medium term, generating companies whose plants need periodic 
maintenance require nodal price forecast in order to determine the time to take their plants offline that will have the least impact on their profit levels. In the longer term, potential investors in new or existing power plants also need forecasts of nodal prices in order to determine the potential profitability of (and return on) their investment. Many other industries use and pay for electricity as an important input in their operations, and they also require forecasts of nodal prices in order to determine their own profitability. In many markets around the world, these users are able to purchase contracts for electricity at a fixed price over a specified time period. The valuation of such financial derivatives requires estimation of both the likely levels and volatility of nodal prices in order to determine what that fixed price should be, as well as fair price for the contract itself.

\section{PROBLEM FORMULATION: ELECTRICITY TRANSMISSION PRICING}

\section{AC System Equations}

Let $\mathrm{P}=(\mathrm{p} 1, \ldots \ldots, \mathrm{pn})$ and $\mathrm{Q}=(\mathrm{q} 1, \ldots \ldots, \mathrm{qn})$ for $\mathrm{n}$ bus system, where $\mathrm{p}_{i}$ and $\mathrm{q}_{i}$ be active and reactive power demands of bus-i respectively. The variables in power system operation to be $\mathrm{X}$ $=\left(\mathrm{x}_{1}, \ldots, \mathrm{x}_{\mathrm{m}}\right)$, i.e. real and imaginary bus voltages. Then the operational problem of a power system for given load $(\mathrm{P}, \mathrm{Q})$ can be formulated as OPF problem,

$$
\text { Minimize } f(\mathrm{X}, \mathrm{P}, \mathrm{Q}) \quad \text { for } \mathrm{X}
$$

$$
\text { Subject to } \mathrm{S}(\mathrm{X}, \mathrm{P}, \mathrm{Q})=0
$$

$$
\mathrm{T}(\mathrm{X}, \mathrm{P}, \mathrm{Q}) \leq 0
$$

Where $S(X)=\left(s_{1}(X, P, Q), \ldots \ldots, s_{n 1}(X, P, Q)\right)^{T}$ and $T(X)$ $=\left(t_{1}(X, P, Q), \ldots \ldots, t_{n 2}(X, P, Q)\right)^{T}$ have $n_{1}$ and $n_{2}$ equations respectively, and are column vectors. Here $\mathrm{A}^{\mathrm{T}}$ represents the transpose of vector A.

$f(\mathrm{X}, \mathrm{P}, \mathrm{Q})$ is a scalar, short term operating cost, such as fuel cost. The generator cost function $f_{i}\left(P_{G i}\right)$ in $\$ / \mathrm{MWh}$ is considered to have cost characteristics represented by,

$$
f=\sum_{i=1}^{N G} a_{i} P_{G i}^{2}+b_{i} P_{G i}+c_{i}
$$

Where, $P_{G i}$ is the real power output; $a_{i}, b_{i}$ and $c_{i}$ represents the cost coefficient of the $i^{\text {th }}$ generator, $N G$ represents the generation buses,

The constraints to be satisfied during optimization are,

(1) Vector of equality constraint such as power flow balance (i.e. Kirchoff's laws) has represented by,

$$
\mathrm{S}(\mathrm{X}, \mathrm{P}, \mathrm{Q})=0 \text { or }
$$$$
P_{G}=P_{D}+P_{D C}+P_{L} \text { and } Q_{G}=Q_{D}+Q_{D C}+Q_{L}
$$

(5)

Where suffix $D$ represents the demand, $G$ is the generation, $D C$ represents de terminal and $L$ is the transmission loss.

(2) The vector of inequality constraints includes all variables and function limits, such as upper and lower bounds of transmission lines, generation outputs, stability and security limits may be represented as, (i) The maximum and minimum real and reactive power outputs of the generating sources have given by,

$$
\begin{aligned}
P_{G i}^{\min } \leq & P_{G i} \leq P_{G i}^{\max }\left(i \in G_{B}\right) \\
& \text { and } Q_{G i}^{\min } \leq Q_{G i} \leq Q_{G i}^{\max } \quad\left(i \in G_{B}\right)
\end{aligned}
$$

Where, $P_{G i}^{\min }, P_{G i}^{\max }$ are the minimum and maximum real power outputs of the generators and $Q_{G i}^{\min }, Q_{G i}^{\max }$ are the minimum and maximum reactive power outputs.

(ii) Voltage limits (Min/Max) signals the system bus voltages to remain within a narrow range. It is denoted by the following constraints,

$$
\left|V_{i}^{\min }\right| \leq\left|V_{i}\right| \leq\left|V_{i}^{\max }\right| \quad\left(\mathrm{i}=1, \ldots \ldots, \mathrm{N}_{\mathrm{B}}\right)
$$

Where, $\mathrm{N}_{\mathrm{B}}$ represents number of buses.

(iii) Power flow limits is the transmission line's thermal or stability limits capable of transmitting maximum power (MVA) flow through the lines and it is expressed by the following constraints,

$$
P_{f}^{\min } \leq P_{f} \leq P_{f}^{\max } \quad(\mathrm{f}=1, \ldots, \text { Noele })
$$

Where, Noele represents number of transmission lines connected to grid. Then, operating conditions of a combined ac-dc electric power system may described by the vector,

$$
X=\left[\delta, V, x_{c}, x_{d}\right]^{t}
$$

Where, $\delta$ and $V$ are the vectors of the phases and magnitude of the phasor bus voltages; $x_{c}$ is the vector of control variables and $x_{d}$ is the vector of dc variables.

\section{DC System Equations}

The following relationship is for the dc variables. Using the per unit system [14], the average value of the dc voltage of a converter connected to bus ' $i$ ' is

$$
V_{d i}=a_{i} V_{i} \cos \alpha_{i}-r_{c i} I_{d i}
$$

Where, $\alpha_{i}$ is the gating delay angle for rectifier operation or the extinction advance angle for inverter operation; $r_{c i}$ is the commutation resistance, and $a_{i}$ is the converter transformer tap setting. By assuming a lossless converter, the equation of the dc voltage written as,

$$
V_{d i}=a_{i} V_{i} \cos \varphi_{i}
$$

Where, $\varphi_{i}=\delta_{\mathrm{i}}-\xi_{\mathrm{i}}$, and $\varphi$ is the angle by which the fundamental line current lags the line-to-neutral source voltage. The real power flowing in or out of the dc network at terminal ' $\mathrm{i}$ ' may expressed as,

$$
P_{d i}=V_{i} I_{i} \cos \varphi_{i} \quad \text { or } \quad P_{d i}=V_{d i} I_{d i}
$$

The reactive power flow into the de terminal is

$$
Q_{d i}=V_{i} I_{i} \sin \varphi_{i} \text { or } Q_{d i}=V_{i} a I_{i} \sin \varphi_{i}
$$

The equations (13) - (14) can substituted into the equation (5) to form part of the equality constraints. Based on these relationships, the operating condition of the dc system can describe by the vector,

$$
X_{d}=\left[V_{d}, I_{d}, a, \cos \alpha, \varphi\right]^{t}
$$

The dc currents and voltages have related by the dc network equations. In an $\mathrm{AC}$ case, a reference bus is specified 
for each separate dc system; usually the bus of the voltage controlling de terminal operating under constant voltage (or constant angle) control is chosen as the reference bus for that dc network equation.

Equations (1) - (3) are an OPF problem for the demand (P, Q). Many approaches that can be used to get an optimal solution such as linear programming, Newton method, quadratic programming, nonlinear programming, interior point method, artificial intelligence (i.e. artificial neural network, fuzzy logic, genetic algorithm, evolutionary programming, ant colony and particle swarn optimization etc.) methods [16], [22].

\section{E. Electricity Fixed/Embedded Price}

The transmission pricing is in fact the recovery of transmission costs, which include the embedded investment, the running costs incurred on a continuing basis, and the ongoing investment for future expansion or reinforcement [6] The embedded cost methods allocate the embedded capital costs and the average annual maintenance and operation costs of existing facilities to a particular transmission service. As a part of fixed cost, many embedded cost methodologies i.e. Postage Stamp, Contract Path, Boundary Flow, MW-Mile and MVA- Mile have been presented in literature [6], [7], [9], [10]. Due to wide popularity and techno-economic advantages, Postage Stamp, OPF based MW-Mile and MVA-mile methods are formulated as follows,

\section{Postage Stamp Pricing}

It assumes that the entire transmission system is used, irrespective of the actual facilities that carry the transmission service. It is a flat per $\mathrm{kW}$ charge for network access within a particular zone, based on average system cost. It is calculated by summing up all transmission cost divided by system peak demand [9]. The cost $\mathrm{C}$ of the transaction $\mathrm{P}_{\mathrm{w}}$ is calculated as:

$$
\mathrm{C}(\text { Postage Stamp })_{\mathrm{T}}=\frac{\mathrm{P}_{\mathrm{W}}}{\mathrm{P}_{\text {peak }}} \times \frac{\mathrm{C}}{8760}
$$

Where, $\mathrm{C}$ is the total transmission Annual Revenue Requirement (ARR); $\mathrm{C}=\Sigma_{\mathrm{f}} \mathrm{C}_{\mathrm{f}} ; \mathrm{P}_{\text {peak }}$ is the maximum active load of the complete transmission system

\section{MW-Mile Pricing}

In this, the embedded transmission charges are assigned to the customer based mile distance between injection and receipt and the magnitude of transmitted power [9]. Two OPF need to execute i.e. with and without each transaction, yield the changes in MW flows in all transmission lines. The cost $\mathrm{C}$ of the transaction is calculated as:

$$
\mathrm{C}(\mathrm{MW}-\mathrm{Mile})_{\mathrm{T}}=\frac{\mathrm{C} \sum_{\mathrm{f}}^{\sum}\left(\Delta \mathrm{MW}_{\mathrm{f}}\right) T L_{f}}{8760 \sum_{\mathrm{T}}\left(\sum_{f}\left(\Delta \mathrm{MW}_{\mathrm{f}} T^{L_{f}}\right)\right.}
$$

Where: $\Delta \mathrm{MW}_{\mathrm{f}}=\mid \Delta \mathrm{MW}_{\mathrm{f}}$ (with transaction $\left.\mathrm{T}\right)|-| \Delta \mathrm{MW}_{\mathrm{f}}$ (without transaction $\mathrm{T}$ ) $\mid ; \mathrm{L}_{\mathrm{f}}$ is the length of transmission line $\left.\mathrm{f} ;\left(\Delta \mathrm{MW}_{\mathrm{f}}\right\}_{\mathrm{T}} \mathrm{L}_{\mathrm{f}}\right)$ is the $\mathrm{MW}$ flows in facility $\mathrm{f}$ due to transaction $\mathrm{T}$.

\section{MVA- Mile method}

Use of transmission resources is best measured by monitoring both real and reactive power. The cost $\mathrm{C}$ of the transaction is calculated as:

$$
\mathrm{C}(\mathrm{MVA}-\mathrm{Mile})_{\mathrm{T}}=\frac{\mathrm{C} \underset{\mathrm{f}}{\sum}\left(\Delta \mathrm{MVA}_{\mathrm{f}}\right) T L_{f}}{8760 \sum_{\mathrm{T}}\left(\sum_{f}\left(\Delta \mathrm{MVA}_{\mathrm{f}} T_{f} L_{f}\right)\right.}
$$

(18)

Where: $\Delta \mathrm{MVA}_{\mathrm{f}}=\mid \Delta \mathrm{MVA}_{\mathrm{f}}($ with transaction $\mathrm{T})|-| \Delta \mathrm{MVA}_{\mathrm{f}}$ (without transaction $\mathrm{T}$ ) $\mid ; \mathrm{L}_{\mathrm{f}}$ is the length of transmission line $\left.\mathrm{f} ;\left(\Delta \mathrm{MVA}_{\mathrm{f}}\right)_{\mathrm{T}} \mathrm{L}_{\mathrm{f}}\right)$ is the MVA flows in facility $\mathrm{f}$ due to transaction $\mathrm{T}$.

\section{F. Electricity Variable/ Nodal Price}

Nodal pricing is a method to determine market clearing prices for several locations on the transmission grid called nodes. Each node represents a physical location on the transmission system including generators and loads. The price at each node reflects the locational value of energy, which includes the cost of the energy and the cost of delivering it.

In this formulation, the real and reactive power prices at bus ' $i$ ' is the Lagrangian multiplier value of the equality and in-equality constraints. These values have calculated by solving the first order condition of the Lagrangian, partial derivatives of the Lagrangian with respect to every variable concerned. Therefore the Lagrangian function (or system cost) of equation (1) - (3) defined as,

$$
\begin{aligned}
& \mathrm{L}(\mathrm{X}, \lambda, \rho, \mathrm{P}, \mathrm{Q})=\sum_{\mathrm{i}=1}^{\mathrm{NG}} \mathrm{a}_{\mathrm{i}} \mathrm{P}_{\mathrm{Gi}}^{2}+\mathrm{b}_{\mathrm{i}} \mathrm{P}_{\mathrm{Gi}}+\mathrm{c}_{\mathrm{i}}+ \\
& \sum_{\mathrm{i} \in \mathrm{LB}} \lambda \mathrm{pi}\left(\mathrm{P}_{\mathrm{Di}}-\mathrm{P}_{\mathrm{Gi}}+\mathrm{P}_{\mathrm{DCi}}+\mathrm{P}_{\mathrm{Li}}\right)+\sum_{\mathrm{i} \in \mathrm{LB}} \lambda \mathrm{qi}\left(\mathrm{Q}_{\mathrm{Di}}-\mathrm{Q}_{\mathrm{Gi}}+\mathrm{Q}_{\mathrm{DCi}}+\mathrm{Q}_{\mathrm{Li}}\right) \\
& +\sum_{i \in G B} \rho p_{l i}\left(P_{G i}^{\min }-P_{G i}\right)+\sum_{i \in G B} \rho p_{u i}\left(P_{G i}-P_{G i}^{\max }\right)+
\end{aligned}
$$$$
\sum_{i \in G B} \rho q_{l i}\left(Q_{G i}^{\min }-Q_{G i}\right)+\sum_{i \in G B} \rho q_{u i}\left(Q_{G i}-Q_{G i}^{\max }\right)
$$$$
+\sum_{i=1}^{N B} \rho V_{l i}\left(\left|V_{i}^{\min }\right|-\left|V_{i}\right|\right)+\sum_{i=1}^{N B} \rho V_{u i}\left(\left|V_{i}\right|-\left|V_{i}^{\max }\right|\right)+
$$$$
\sum_{i=1}^{N B} \rho \theta_{l i}\left(\theta_{i}^{\min }-\theta_{i}\right)+\sum_{i=1}^{N B} \rho \theta_{u i}\left(\theta_{i}-\theta_{i}^{\max }\right)
$$$$
+\sum_{i=1}^{\text {Noele }} \rho P_{f l i}\left(P_{f i}^{\min }-P_{f i}\right)+\sum_{i=1}^{\text {Noele }} \rho P_{f u i}\left(P_{f i}-P_{f i}^{\max }\right)
$$

(19)

Where, ' $l$ ' and ' $u$ ' are the lower and upper limits; $\lambda=$ $\left(\lambda_{1}, \ldots \ldots, \lambda_{n}\right)$ is the vector of Lagrange multipliers concerning the equality constraints; $\rho=\left(\rho_{1}, \ldots \ldots \ldots, \rho_{n}\right)$ are the Lagrange multipliers concerning to the inequality constraints. Then at an optimal solution $(X, \lambda, \rho)$ and for a set of given $(P, Q)$, the nodal price of real and reactive power for each bus is expressed below for $i=1, \ldots \ldots \ldots, \mathrm{n}$.

$$
\pi_{p, i}=\frac{\partial L(X, \lambda, \rho, P, Q)}{\partial_{p i}}=\frac{\partial f}{\partial_{p i}}+\lambda \frac{\partial S}{\partial_{p i}}+\rho \frac{\partial T}{\partial_{p i}}
$$

$$
\pi_{q, i}=\frac{\partial L(X, \lambda, \rho, P, Q)}{\partial_{q i}}=\frac{\partial f}{\partial_{q i}}+\lambda \frac{\partial S}{\partial_{q i}}+\rho \frac{\partial T}{\partial_{q i}}
$$


Here $\pi_{p, i}$ and $\pi_{q, i}$ are active and reactive nodal prices at bus ' $i$ ', respectively. The difference i.e. $\pi_{p, i}-\pi_{p, j}$ and $\left(\pi_{q, i}-\pi_{q, j}\right)$ represents active and reactive power transmission charges from bus-j to bus-i. Equation (20) can be view as the system marginal cost created by an increment of real power load at bus $i$. The above formulations have simulated in MATLAB programming using the 'fmincon' function. An advantage of it is that the constraints can be directly evaluated as functions of the state variables which can be separate modules reducing programming complexity.

\section{PROBLEM SIMULATION AND NUMERICAL RESULTS}

\section{A. Modified IEEE 30 Bus system}

The given scheme has simulated for modified IEEE 30-Bus system as shown in Fig. A1-Appendix. A HVDC link is connected between bus 1 and bus 30. The ratings of the converter at these buses are 1.0 Per Unit (PU). Table A1-Appendix shows the upper and lower bounds (real power) for generators G1, G2, G13, G22, G23 and G27 and their fuel cost functions expressed as $\left(f_{i}=a_{i} P_{G i}^{2}+b_{i} P_{G i}+c_{i}\right)$ in (\$/MWh). The Real and Reactive power demand is shown in Table A2-Appendix. The upper and lower bounds (reactive power) for all generators are in the range of $-0.5 \leq Q_{G i} \leq 0.5$.

The voltage values for all buses have bounded between 0.95 and 1.05. All values in PU.

Assuming ARR of 1 Billion Dollar, the fixed embedded prices for two simultaneous bilateral transactions is shown in Table I. Postage Stamp prices are calculated without OPF, whereas MW-Mile and MVA-Mile prices are obtained by executing two OPF. The Postage Stamp prices are same at all location on grid. MW-Mile and MVA-Mile prices are comparative and these are based on amount of MW power and distance of injection and receipt of power. MVA-mile considered the effect of reactive power associated with the transaction.

Table I: Transmission Embedded Price

\begin{tabular}{|c|c|c|c|c|c|}
\hline \multirow{2}{*}{$\begin{array}{c}\text { Transaction } \\
\text { (MW) }\end{array}$} & \multirow{2}{*}{$\begin{array}{c}\text { From } \\
\text { Bus }\end{array}$} & \multirow{2}{*}{ To } & \multicolumn{3}{|c|}{ Transmission Price (\$/MWh) } \\
\cline { 4 - 6 } & & $\begin{array}{c}\text { Postage } \\
\text { stamp }\end{array}$ & MW-Mile & MVA-Mile \\
\hline 110 & 1 & 28 & 245 & 252.84 & 254.31 \\
\hline 100 & 2 & 6 & 245 & 281.26 & 279.30 \\
\hline
\end{tabular}

The transmission variable prices are simulated with nodal pricing methodology. Fig.1 and Table II shows bus voltage behaviour and electricity nodal prices with and without simultaneous bilateral Transactions (Tr.) respectively. The voltages at several buses without transaction are improved one. The electricity nodal prices obtained at all buses are lower compared with simultaneous bilateral transactions.

Table II: Electricity Nodal Prices and Voltage Behaviour

\begin{tabular}{|c|c|c|c|c|c|}
\hline \multirow{2}{*}{$\begin{array}{l}\text { Bus } \\
\text { No. }\end{array}$} & \multicolumn{2}{|c|}{ Nodal Price (\$/MWh) } & \multirow{2}{*}{$\begin{array}{l}\text { Bus } \\
\text { No. }\end{array}$} & \multicolumn{2}{|c|}{ Nodal Price (\$/MWh) } \\
\hline & $\begin{array}{c}\text { Without } \\
\text { Tr. }\end{array}$ & With Tr. & & $\begin{array}{c}\text { Without } \\
\text { Tr. }\end{array}$ & With Tr. \\
\hline 1 & 19.85 & 19.89 & 16 & 20.34 & 20.37 \\
\hline
\end{tabular}

\begin{tabular}{|l|l|l|l|l|l|}
\hline 2 & 19.82 & 19.86 & 17 & 20.26 & 20.29 \\
\hline 3 & 20.09 & 20.13 & 18 & 20.61 & 20.65 \\
\hline 4 & 20.15 & 20.18 & 19 & 20.64 & 20.67 \\
\hline 5 & 21.30 & 21.47 & 20 & 20.52 & 20.55 \\
\hline 6 & 20.21 & 20.25 & 21 & 19.77 & 19.78 \\
\hline 7 & 20.75 & 20.84 & 22 & 19.58 & 19.58 \\
\hline 8 & 20.22 & 20.26 & 23 & 20.03 & 20.06 \\
\hline 9 & 20.14 & 20.18 & 24 & 19.89 & 19.91 \\
\hline 10 & 20.11 & 20.14 & 25 & 19.54 & 19.55 \\
\hline 11 & 20.14 & 20.18 & 26 & 19.47 & 19.47 \\
\hline 12 & 20.30 & 20.34 & 27 & 19.38 & 19.39 \\
\hline 13 & 20.30 & 20.34 & 28 & 20.21 & 20.25 \\
\hline 14 & 20.57 & 20.62 & 29 & 19.55 & 19.61 \\
\hline 15 & 20.42 & 20.45 & 30 & 19.54 & 19.63 \\
\hline
\end{tabular}

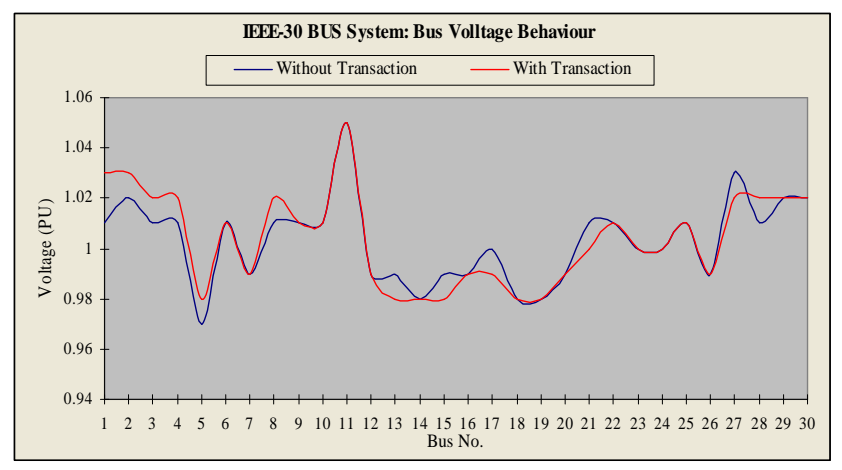

Fig.1: Bus Voltage Behaviour

\section{B. Indian Electricity Market: An overview}

India's electricity sector has grown to $143,061 \mathrm{MW}$ as on $31^{\text {st }}$ March 2008 with a compound annual growth rate of $8-9 \%$. This sector is been characterized by shortage of supply vis-à-vis demand. In order to improve its performances, GoI have been initiating electricity sector restructuring since 1991. The EA 2003 is been brought to facilitate private investments to envisages competition in electricity market, protection of consumer's interests and provision of power for all.

On the electricity transmission front, the National grid in the country is characterized by interconnection between Western, Northern, and North-Eastern regions of India, whereas Southern region is operating in asynchronous mode. Each one has number of constituent sub grids formed by state and private utility networks. All these sub grids and networks have connected to form a $400 \mathrm{kV}$ national grid. The constituent systems have their own generation in additional to generation by central government undertakings in different parts of the country and feeds power in the grid at different locations. The Central and State Transmission Utility (STU) is responsible for the national and regional transmission system development and is also providing Open Access on it's inter and intra-state transmission system. To increase efficiency and competition Central Electricity Regulatory Commission allowed open access, inter-regional electricity transmission linkages and implemented Availability Based Tariff for real time balancing market. To promote power trading in a free power market, CERC recently setup Indian Energy Exchange (IEX) for providing price discovery and price risk management to the electricity generators, distribution licensees, electricity traders, consumers and 
other stakeholders. At present, IEX offers day-ahead contracts whose time line is set in accordance with the operations of Regional Load Dispatch Centers (RLDCs). IEX coordinates with the National Load Dispatch Centers/RLDCs and State LDCs for scheduling of traded contracts.

\section{Real Transmission Network of India}

Maharashtra State Electricity Transmission Company Limited (MSETCL) is the largest state transmission utility in India with $498 \mathrm{EHV}$ substations with transformation capacity of around 61,500 MVA and EHV lines of around 36,300 Ckm. Further, MSETCL has installed 9000 ABT meters for proper energy accounting and transmission loss evaluation purpose. MSETCL is the only state transmission utility in India which is operating and maintaining $+/-500 \mathrm{kV}, 1500$ MW HVDC bipole line between Chandrapur and Padghe. This link transfers bulk power from eastern side of Maharashtra to load centre located in Western Maharashtra.

This study considered a real network of $400 \mathrm{kV}$ MSETCL shown in Fig. B1-Appendix. It consists of 19 intra-state and 8 inter-state buses. Additional power to fulfill real power demand is imported from inter-state generators namely BHILY, KHANDWA, SDSRV, BOISR, BDRVT, TARAPUR, and SATPR. The generator installed capacity, upper and lower bounds for generators, fuel cost function for intra and inter-state generators expressed as $\left(f_{i}=a_{i} P_{G i}^{2}+b_{i} P_{G i}+c_{i}\right)$ in $(\$ / \mathrm{MWh})$ is given in Table $\mathrm{B} 1-\mathrm{Appendix}$. The real and reactive power peak demand is shown in Table B2-Appendix. The voltages at all buses have bounded between 0.95 and $1.05 \mathrm{PU}$. The operating data for HVDC link has shown in Table B3-Appendix. CHDPUR selected as a reference bus. The MSETCL's expenses as a part of ARR are shown in Table B4-Appendix.

The fixed embedded prices i.e. Postage Stamp, MW-Mile and MVA-Mile prices for two simultaneous bilateral transactions are shown in Table III. Again MW-Mile and MVA-Mile prices are comparative and these are based on amount of MW power and distance of injection and receipt of power.

Table III: MSETCL: Transmission Embedded Price

\begin{tabular}{|c|c|c|c|c|c|}
\hline \multirow{2}{*}{$\begin{array}{l}\text { Transacti } \\
\text { on (MW) }\end{array}$} & \multirow{2}{*}{$\begin{array}{c}\text { From } \\
\text { Bus }\end{array}$} & \multirow{2}{*}{$\begin{array}{l}\text { To } \\
\text { Bus }\end{array}$} & \multicolumn{3}{|c|}{$\begin{array}{c}\text { Transmission Price } \\
(\$ / M W h)\end{array}$} \\
\hline & & & $\begin{array}{c}\text { Postag } \\
\text { e } \\
\text { Stamp }\end{array}$ & $\begin{array}{l}\text { MW-M } \\
\text { ile }\end{array}$ & $\begin{array}{l}\text { MVA- } \\
\text { Mile }\end{array}$ \\
\hline 110 & KORDY & $\begin{array}{c}\text { ARGBD } \\
4\end{array}$ & 76.93 & 210.21 & 210.55 \\
\hline 100 & $\begin{array}{c}\text { CHDPU } \\
\mathrm{R} \\
\end{array}$ & $\begin{array}{c}\text { PARLY } \\
2 \\
\end{array}$ & 76.93 & 191.10 & 191.00 \\
\hline
\end{tabular}

The transmission variable/nodal prices with and without (W/o) simultaneous bilateral transaction (Tr.) are shown in Table IV. The bus voltages and nodal prices without simultaneous bilateral transaction are improved compared with transaction.

Table IV: Electricity Nodal Price $(\$ / \mathrm{MWh})$ at Peak Load

\begin{tabular}{|c|c|c|c|c|c|c|}
\hline \multirow{3}{*}{ Bus Name } & \multicolumn{2}{|c|}{ Voltage (PU) } & \multicolumn{3}{c|}{ Nodal Price (\$/MWh) } \\
\cline { 2 - 7 } & \multicolumn{2}{|c|}{} & \multicolumn{2}{|c|}{ Real } & \multicolumn{2}{c|}{ Reactive } \\
\cline { 2 - 7 } & W/o & With & W/o & With & W/o & With \\
& Tr. & Tr. & Tr. & Tr. & Tr. & Tr. \\
\hline
\end{tabular}

\begin{tabular}{|l|l|l|l|l|l|l|}
\hline CHDPUR & 1.03 & 1.02 & 22.90 & 23.15 & 0.00 & 0.00 \\
\hline KORDY & 1.05 & 1.00 & 22.96 & 22.69 & 0.00 & 0.00 \\
\hline BHSWL2 & 1.01 & 0.97 & 24.34 & 29.41 & 0.39 & 0.30 \\
\hline ARGBD4 & 0.99 & 0.96 & 24.82 & 29.54 & 0.41 & 0.47 \\
\hline BBLSR2 & 1.01 & 0.99 & 24.87 & 29.01 & 0.30 & 0.51 \\
\hline DHULE & 1.05 & 1.04 & 25.07 & 29.28 & 0.00 & 0.15 \\
\hline PADGE & 0.99 & 0.98 & 24.59 & 27.90 & 0.46 & 0.89 \\
\hline KALWA & 0.99 & 0.98 & 24.60 & 27.87 & 0.46 & 0.90 \\
\hline KARGAR & 0.98 & 0.97 & 24.61 & 27.89 & 0.48 & 0.93 \\
\hline LONKAND & 1.00 & 0.99 & 24.13 & 26.75 & 0.24 & 0.58 \\
\hline NGOTNE & 0.99 & 0.99 & 25.44 & 29.33 & 0.27 & 0.53 \\
\hline DABHOL & 1.01 & 1.02 & 26.30 & 30.81 & 0.00 & 0.07 \\
\hline KOYNA-N & 1.01 & 1.01 & 26.69 & 31.47 & 0.00 & 0.00 \\
\hline KOYNA-4 & 1.01 & 1.01 & 20.94 & 20.94 & 0.00 & 0.00 \\
\hline KLHPR3 & 1.03 & 1.03 & 26.20 & 30.35 & 0.00 & 0.00 \\
\hline JEJURY & 0.99 & 0.99 & 22.65 & 23.95 & 0.15 & 0.37 \\
\hline KARAD2 & 1.01 & 1.01 & 26.18 & 30.38 & 0.00 & 0.00 \\
\hline SOLPR3 & 1.00 & 0.99 & 25.42 & 28.61 & 0.02 & 0.38 \\
\hline PARLY2 & 1.03 & 1.01 & 24.14 & 26.05 & 0.12 & 0.69 \\
\hline
\end{tabular}

Fig 2 shows the inter-state power purchase behaviour with and without given transaction. Lower cost interstate generator is effectively utilized with two simultaneous bilateral transactions.

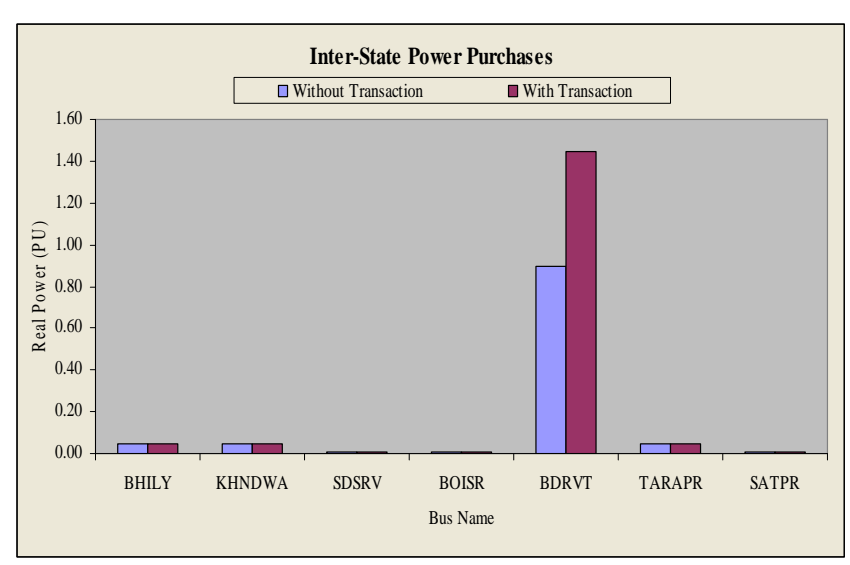

Fig. 2 Inter-state Power Purchase/Import Behaviour

\section{CONCLUSION}

In this paper an AC-DC OPF based transmission fixed embedded and variable nodal pricing methodology is presented. Simulated results show that Postage Stamp, MW-Mile and MVA-Mile and electricity nodal pricing is suitable for real transmission network in developing countries including India. These pricing methods can able to fulfill transmission pricing objectives i.e. economic efficiency, non-discrimination, transparency and cost coverage etc., in developing wholesale electricity market in developing countries. 
APPENDIX

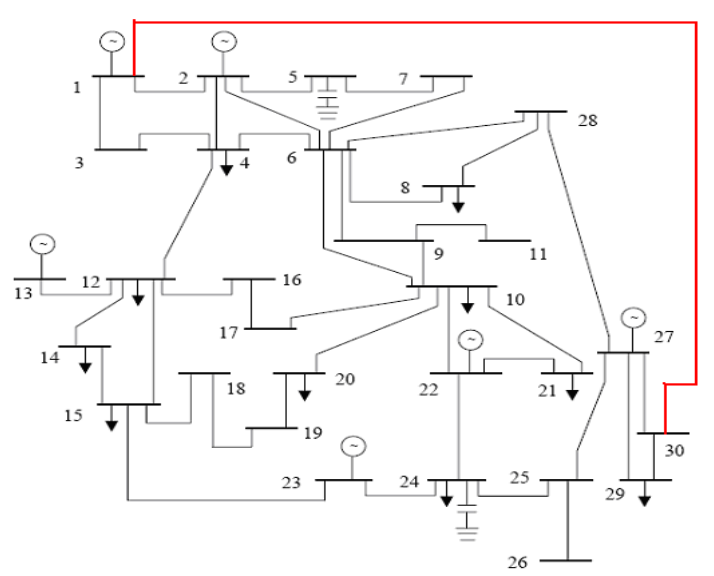

Fig. A1: Modified IEEE 30-bus test system

Table A1: Real Power and Fuel cost of generator

\begin{tabular}{|c|c|c|c|c|c|}
\hline \multirow{2}{*}{$\begin{array}{c}\text { Bus No. } \\
\text { (Generator) }\end{array}$} & \multirow{2}{*}{$\begin{array}{c}\text { Lower Limit } \\
\text { (Real }\end{array}$} & \multirow{2}{*}{$\begin{array}{c}\text { Upper Limit } \\
\text { (Real }\end{array}$} & \multicolumn{3}{|c|}{ Generation cost } \\
\cline { 4 - 6 } & Power) & Power) & $\mathrm{a}_{\mathrm{i}}$ & $\mathrm{b}_{\mathrm{i}}$ & $\mathrm{c}_{\mathrm{i}}$ \\
\hline 1 & 0.1 & 1.5 & 0.14 & 20.4 & 5.0 \\
\hline 2 & 0.1 & 1.5 & 0.20 & 19.3 & 5.0 \\
\hline 13 & 0.1 & 1.0 & 0.14 & 20.4 & 5.0 \\
\hline 22 & 0.1 & 1.5 & 0.20 & 19.3 & 5.0 \\
\hline 23 & 0.1 & 1.0 & 0.14 & 20.4 & 5.0 \\
\hline 27 & 0.1 & 1.5 & 0.20 & 19.3 & 5.0 \\
\hline
\end{tabular}

Table A2: Demand $\left(p_{i}+j q_{i}\right)$ for IEEE 30-Bus System

\begin{tabular}{|c|r|c|c|c|r|}
\hline Bus & \multicolumn{1}{|c|}{ Demand } & Bus & \multicolumn{1}{c|}{ Demand } & Bus & \multicolumn{1}{c|}{ Demand } \\
\hline 1 & $0.0+\mathrm{j} 0.0$ & 11 & $0.0-\mathrm{j} 0.177$ & 21 & $0.175+\mathrm{j} 0.112$ \\
\hline 2 & $0.217+\mathrm{j} 0.13$ & 12 & $0.112+\mathrm{j} 0.0$ & 22 & $0.00+\mathrm{j} 0.00$ \\
\hline 3 & $0.024+\mathrm{j} 0.012$ & 13 & $0.00-\mathrm{j} 0.155$ & 23 & $0.032+\mathrm{j} 0.016$ \\
\hline 4 & $0.076+\mathrm{j} 0.016$ & 14 & $0.062+\mathrm{j} 0.016$ & 24 & $0.087+\mathrm{j} 0.067$ \\
\hline 5 & $0.942+\mathrm{j} 0.019$ & 15 & $0.082+\mathrm{j} 0.025$ & 25 & $0.0+\mathrm{j} 0.0$ \\
\hline 6 & $0.0+\mathrm{j} 0.0$ & 16 & $0.035+\mathrm{j} 0.018$ & 26 & $0.035+\mathrm{j} 0.023$ \\
\hline 7 & $0.228+\mathrm{j} 0.109$ & 17 & $0.090+\mathrm{j} 0.058$ & 27 & $0.0-\mathrm{j} 0.10$ \\
\hline 8 & $0.30-\mathrm{j} 0.30$ & 18 & $0.032-\mathrm{j} 0.009$ & 28 & $0.0+\mathrm{j} 0.0$ \\
\hline 9 & $0.0+\mathrm{j} 0.0$ & 19 & $0.095+\mathrm{j} 0.034$ & 29 & $0.024+\mathrm{j} 0.009$ \\
\hline 10 & $0.058+\mathrm{j} 0.0$ & 20 & $0.022+\mathrm{j} 0.007$ & 30 & $0.106+\mathrm{j} 0.0$ \\
\hline
\end{tabular}

\section{(B) A Real Network of $400 \mathrm{kV}$, MSETCL, India:}

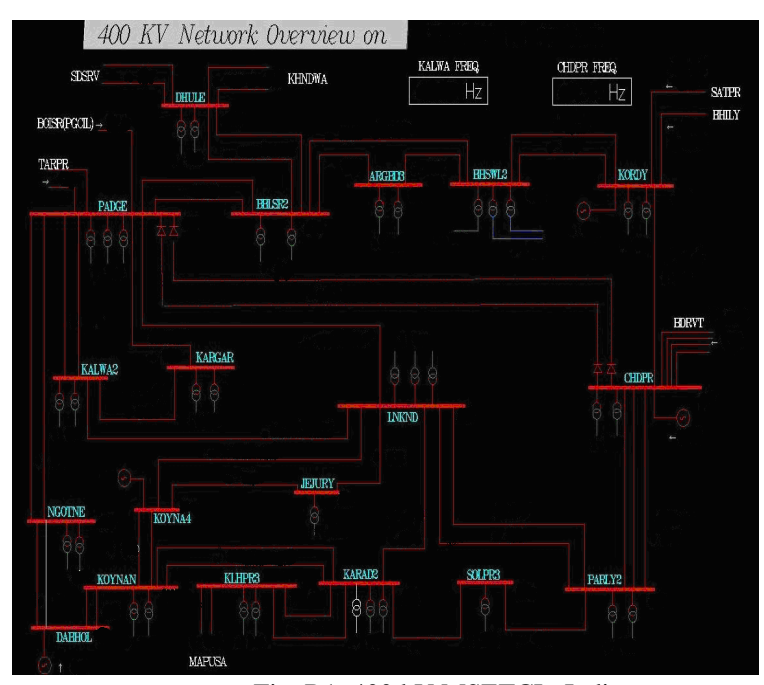

Fig. B1: 400 kV MSETCL, India
Table B1: Generation Capacity, Costs and Peak Demand $\left(\mathrm{P}_{\mathrm{L}}\right)$

\begin{tabular}{|c|c|c|c|c|c|c|c|c|}
\hline \multirow{3}{*}{$\begin{array}{c}\text { Bus/ } \\
\text { Generator }\end{array}$} & \multirow{3}{*}{$\begin{array}{l}\text { Gen. } \\
\text { Cap. }\end{array}$} & \multicolumn{4}{|c|}{ Generation (PU) } & \multirow{2}{*}{\multicolumn{3}{|c|}{$\begin{array}{c}\text { Generation cost } \\
(\$ / \mathrm{MWh})\end{array}$}} \\
\hline & & \multicolumn{2}{|c|}{$\mathrm{P}$} & \multicolumn{2}{|c|}{$\mathrm{Q}$} & & & \\
\hline & & Max & Min & Max & Min & $\mathrm{a}_{\mathrm{i}}$ & $b_{i}$ & $\mathrm{c}_{\mathrm{i}}$ \\
\hline \multicolumn{9}{|c|}{ Intra-State Generators } \\
\hline CHDPUR & 2.3 & 1.72 & 0.2 & 1.0 & -1.0 & 0.2 & 20.4 & 10.2 \\
\hline KORDY & 1.1 & 0.54 & 0.2 & 0.5 & -0.5 & 0.2 & 22.4 & 10.2 \\
\hline DABHOL & 1.2 & 1.44 & 0.2 & 0.1 & -0.1 & 1.0 & 71.4 & 10.2 \\
\hline KOYNA-4 & 1.5 & 0.19 & 0.1 & 0.1 & -0.1 & 0.2 & 20.4 & 10.2 \\
\hline \multicolumn{9}{|c|}{ Intra-State Generators } \\
\hline BHILY & & 0.6 & 0.1 & 0.1 & -0.1 & 0.2 & 36.9 & 10.2 \\
\hline KHANDW & & 0.7 & 0.2 & 0.5 & -0.5 & 1.0 & 36.9 & 10.2 \\
\hline SDSRV & & 0.5 & 0.01 & 0.1 & -0.1 & 1.0 & 77.6 & 10.2 \\
\hline BOISR & & 0.2 & 0.01 & 0.1 & -0.1 & 1.0 & 55.7 & 10.2 \\
\hline BDRVT & & 1.7 & 0.2 & 0.1 & -0.1 & 0.2 & 22.5 & 10.2 \\
\hline $\begin{array}{l}\text { TARAPU } \\
\mathrm{R} \\
\end{array}$ & & 0.4 & 0.01 & 0.1 & -0.1 & 1.0 & 58.6 & 10.2 \\
\hline SATPR & & 0.2 & 0.01 & 0.1 & -0.1 & 1.0 & 55.7 & 10.2 \\
\hline
\end{tabular}

Table B2: Peak Demand $\left(\mathrm{P}_{\mathrm{L}}\right)$

\begin{tabular}{|l|c|c|l|c|c|}
\hline \multirow{2}{*}{ Bus Name } & \multicolumn{2}{|c|}{$\begin{array}{c}\text { Demand } \\
\text { (PU) }\end{array}$} & Bus Name & \multicolumn{2}{c|}{$\begin{array}{c}\text { Demand } \\
\text { (PU) }\end{array}$} \\
\hline & $\mathrm{P}$ & $\mathrm{Q}$ & & $\mathrm{P}$ & $\mathrm{Q}$ \\
\hline CHDPUR & 0.32 & 0.10 & NGOTNE & 0.17 & 0.18 \\
\hline KORDY & 0.27 & 0.10 & DABHOL & 0.00 & 0.00 \\
\hline BHSWL2 & 0.22 & 0.10 & KOYNA-N & 0.05 & 0.00 \\
\hline ARGBD4 & 0.37 & 0.21 & KOYNA-4 & 0.00 & 0.00 \\
\hline BBLSR2 & 0.37 & 0.17 & KLHPR3 & 0.19 & 0.01 \\
\hline DHULE & 0.35 & 0.15 & JEJURY & 0.34 & 0.10 \\
\hline PADGE & 0.54 & 0.15 & KARAD2 & 0.34 & 0.12 \\
\hline KALWA & 0.38 & 0.15 & SOLPR3 & 0.39 & 0.11 \\
\hline KARGAR & 0.10 & 0.15 & PARLY2 & 0.28 & 0.01 \\
\hline LONKAND & 0.55 & 0.23 & & & \\
\hline
\end{tabular}

Table B3: $\pm 500 \mathrm{kV}$ CHDPUR-PADGE HVDC Link

\begin{tabular}{|c|c|c|c|}
\hline Particulars & Data & Particulars & Data \\
\hline $\begin{array}{l}\text { Power Flow } \\
\text { Rating }\end{array}$ & $\begin{array}{l}1500 \\
\text { MW }\end{array}$ & $\begin{array}{l}\text { Thyristor Valves } \\
\text { Max. voltage } \\
\text { Rated current }\end{array}$ & $\begin{array}{l}7 \mathrm{kV} \\
1700 \\
\text { Adc } \\
\end{array}$ \\
\hline $\begin{array}{l}\text { Converter } \\
\text { X'mer } \\
\text { Voltage of each } \\
\text { pole } \\
\text { Rated power of } \\
\text { unit }\end{array}$ & $\begin{array}{l}500 \mathrm{kV} \\
298.6 \\
\text { MVA }\end{array}$ & $\begin{array}{l}\text { Resistance } \\
\text { (1-Pole) } \\
\text { (2-Pole) } \\
\text { Metallic Return }\end{array}$ & $\begin{array}{l}7.5 \\
\text { Ohms } \\
7.5 \\
\text { Ohms } \\
15 \\
\text { Ohms } \\
\end{array}$ \\
\hline $\begin{array}{l}\text { HVDC Line } \\
\text { Length of line } \\
\text { Number of } \\
\text { poles } \\
\text { Nominal DC } \\
\text { voltage }\end{array}$ & $\begin{array}{l}753 \mathrm{Km} \\
2 \\
\pm 500 \mathrm{Kv}\end{array}$ & $\begin{array}{l}\text { Operation } \\
\text { CHDPUR-Converter/Rectifier } \\
\text { PADGE-Inverter }\end{array}$ & $\begin{array}{l}12.5 \text { to } \\
15 \\
\text { degree } \\
17 \text { to } \\
22 \\
\text { degree }\end{array}$ \\
\hline
\end{tabular}

Table B4: MSETCL Expenses (Billion Dollar) (2008-09)

\begin{tabular}{|l|l|r|r|}
\hline SN & \multicolumn{1}{|c|}{ Particulars } & $\begin{array}{c}\text { All } \\
\text { Networks }\end{array}$ & $\begin{array}{c}\text { 400 kV } \\
\text { Network }\end{array}$ \\
\hline 1 & Operations \& maintenance expenses & 344.96 & 172.48 \\
\hline 1.1 & Employee Expenses & 163.17 & 81.83 \\
\hline 1.2 & Administration \& General Expenses & 26.95 & 13.72 \\
\hline 1.3 & Repair \& Maintenance Expenses & 155.33 & 77.42 \\
\hline 2 & Depreciation and advances & 186.2 & 93.1 \\
\hline 3 & Interest on Long-term Load Capital & 80.36 & 40.18 \\
\hline
\end{tabular}




\begin{tabular}{|l|l|r|r|}
\hline 4 & Interest on working capital & 28.91 & 14.21 \\
\hline 5 & Other Interest and Finance Charges & 19.6 & 10.29 \\
\hline 6 & Other Expenses & 0.49 & 0.343 \\
\hline 7 & Income Tax & 53.9 & 26.95 \\
\hline 8 & $\begin{array}{l}\text { Contribution to contingency } \\
\text { reserves }\end{array}$ & 24.5 & 12.25 \\
\hline & Total Expenses & 738.92 & 368.48 \\
\hline
\end{tabular}

\section{ACKNOWLEDGMENT}

Authors are thankful to the authorities of MSETCL (STU), and MAHAGENCO for providing technical and commercial data for completion of this paper.

\section{REFERENCES}

[1] F.F Wu, F.L. Zheng, F.S. Wen, "Transmission investment and expansion planning in a restructured electricity market", Energy 31, 2006, pp. 954-966.

[2] F. C. Schweppe, M.C. Caramanis, and R.E. Bohn, "The cost of Wheeling and optimal Wheeling Rates" IEEE Trans. on PWRS Vol.1, No. 1, Feb 1986.

[3] Hyde M. Merrill, Bruce W. Erickson, "Wheeling Rates Based on Marginal cost Theory", IEEE Trans. on Power System, Vol.4, No. 4 Oct 1989.

[4] D. Shirmohammmadi, C. Rajgopalan, E.R. Alward and C. L. Thomas "Cost of Transmission Transaction: Introduction", IEEE Trans. on Power System, Vol.6 No.4, Nov 1991, pp. 1546-1560.

[5] Ross Kovacs, Allen Leverett, “ A Load Flow Based Method for calculating Embedded, Incremental and Marginal cost of Transmission capacity", IEEE Trans. on Power System, Vol.9, No. 1, Feb 1994, pp. 272-278.

[6] Happ, "Cost of Wheeling Methodologies", IEEE Trans. on Power System, Vol.9, No. 1, Feb 1994.

[7] J.W. Marangon Lima, "Allocation of transmission Fixed Charges: An Overview" IEEE Trans. on Power Systems, Vol.11, No. 3, August 1996, pp. 1409-1415.

[8] Young-Moon Park; Jong-Bae Park; Jung-Uk Lim; Jong-Ryul Won “An analytical approach for transaction costs allocation in transmission system”, IEEE Trans. on Power Systems, Volume: 13 Issue 4, Nov. 1998, pp. $1407-1412$.

[9] Yog Raj Sood, N. Padhy, H.O. Gupta, “ Allocating Embedded Cost of transmission to Simultaneous Bilateral Transactions- An Applications to South African System" Journal of the International Associations on Electricity Generation Transmission and Distribution (Afro Asian Region), Vol 8-10, No 1, March-June 2002, pp. 1-11.

[10] M. Oloomi-Buygi, and M. Reza Salehizadeh, "Transmission Pricing based on Voltage Angle Decomposition", Proceedings of World Academy of Science, Engineering and Technology Volume 17, December 2006, pp. 151-156.

[11] M. Rivier and I. J. Perez-Ariaga, "Computation and decomposition of nodal price far transmission pricing," in 11th PSCC conference, 1991.

[12] D. Finney, H. A. Othman, and W. L. Rutz, "Evaluating transmission congestion constraints in system planning," IEEE Trans. on Power Systems, vol. 12, no. 3, Aug. 1997.

[13] F.C. Schweppe, M.C. Caramanis, R.D. Tabors, and R.E. Bohn, Nodal Pricing of Electricity, Norwell, MA: Kluwer, 1988.

[14] C. N. Lu, S. S. Chen, C. M. Ong, "The Incorporation of HVDC Equations in Optimal Power Flow Methods using Sequential Quadratic Programming Techniques", IEEE Trans. on Power Systems, Vol. 3, No.3, August 1988, pp 1005-1011.

[15] Kai Xie, Yong-Hua Song, John Stonham, Erkeng Yu, and Guangyi Liu, "Decomposition Model and Interior Point Methods for Optimal Nodal Pricing of Electricity in Deregulation Environments", IEEE Trans. on Power Systems, vol. I, No. 1, February 2000, pp. 39-50.

[16] Luonan Chen, Hideki Suzuki, Tsunehisa Wachi, and Yukihiro Shimura, "Components of Nodal Prices for Electric Power Systems", IEEE Trans. on Power Systems, Vol. 17, No. 1, 2002, pp. 41-49.

[17] Eugene Litvinov, Tongxin Zheng, Gary Rosenwald, and Payman Shamsollahi, "Marginal Loss Modeling in LMP Calculation", IEEE Trans. on Power Systems, Vol. 19, No. 2, May 2004, pp. 880-888.

[18] Tong Wu, Ziad Alaywan, and Alex D. Papalexopoulos, "Locational Marginal Price Calculations Using the Distributed-Slack Power-Flow Formulation", IEEE Trans. on Power Systems, Vol. 20, No. 2, May 2005, pp. 1188-1190.
[19] Hugo A. Gil, Francisco D. Galiana, and Edson L. da Silva, "Nodal Price Control: A Mechanism for Transmission Network Cost Allocation", IEEE Trans. on Power Systems, Vol. 21, No. 1, February 2006, pp. 3-10.

[20] Guang Li, Chen-Ching Liu, Chris Mattson, and Jacques Lawarrée, "Day-Ahead Electricity Price Forecasting in a Grid Environment", IEEE Trans. on Power Systems, Vol. 22, No. 1, February 2007, pp. 266-274.

[21] Fangxing Li, and Rui Bo, "DCOPF-Based LMP Simulation: Algorithm, Comparison with ACOPF, and Sensitivity", IEEE Trans. on Power Systems, Vol. 22, No. 4, November 2007, pp. 1475-1485.

[22] Pandya K.S., Joshi S. K., "A survey of Optimal Power Flow Methods", Journal of Theoretical and Applied Information Technology, 2008, pp, 450- 458 .

S. B. Warkad received the B.E. and M.E degrees in Electrical Power System from the Amravati University and M.B.A. degree from Nagpur University, India. He is presently persuing his Ph.D., degree at Visvesvaraya National Institute of Technology, Nagpur, India. He has published more than 25 research papers in different International and National Journals and Conference Proceedings. His main research interest includes power system restructuring, planning, operation and control.

Dr. M. K. Khedkar received the B.E., M.Tech., and Ph.D. degrees in Electrical Engineering from Visvesvaraya National Institute of Technology, Nagpur, India. He is now the head of Electrical Engineering Department, Visvesvaraya National Institute of Technology, Nagpur, India. He has published more than 100 research papers in different International and National Journals and Conference Proceedings. His main research interest includes power system planning, operation and control, and Energy Management.

Dr. G. M. Dhole, received the B.E., M.Tech., from Visvesvaraya National Institute of Technology, Nagpur, India. Ph.D. degree in Electrical Engineering from Amravati University, India. He is now the Professor at Electrical Engineering Department, Shri Sant Gajanan Maharaj College of Engineering, Shegaon, India. He has published more than 50 research papers in different International and National Journals and Conference Proceedings. His main research interest includes power system planning, operation and control, intelligent methods and its applications in power system. 